\title{
Changes in the Oxygen Regime in the Deep Part of the Black Sea in 1980-2019
}

\author{
A. V. Vidnichuk ${ }^{凶}$, S. K. Konovalov \\ Marine Hydrophysical Institute of RAS, Sevastopol, Russian Federation \\ 凶anna_vidnichuk@mhi-ras.ru
}

Purpose. Assessing changes in the oxygen regime of the deep-water part of the Black Sea under the influence of climatic and anthropogenic factors over the past 40 years is the goal of the work. Methods and Results. For the analysis, the expedition data (2015-2019) and those from the Databank of the Marine Hydrophysical Institute, Russian Academy of Sciences, (1980-2013) were used. The data for the deep-water part of the Black Sea (the depths exceeding $200 \mathrm{~m}$ ) were selected from the array. The data on hydrophysical and hydrochemical parameters were subjected to expert assessment, and those including random errors in the values were excluded from the array. Then the average profiles of temperature, salinity, oxygen concentration, oxygen saturation, and nitrates concentration were plotted in the density scale $\left(\sigma_{t}\right)$. Averaging was carried out by the inverse distance method followed by additional smoothing by the low-frequency filtering method.

Conclusions. Against the background of the tendency of temperature increase in the upper layers of the water column and decrease of winter convective mixing intensity, the oxygen supply diminishes in all the layers of the Black Sea aerobic zone. Having been analyzed, of the data for the 1980-2019 period showed that at the present stage, a "regime shift" resulting from the joint effect of climate changes and anthropogenic load took place in the ecosystem of the deep-water part of the Black Sea. Decrease in the oxygen saturation of water throughout the entire thickness of the aerobic zone shows that the process of the Black Sea basin eutrophication constitutes a significant factor affecting oxygen dynamics in the Black Sea waters.

Keywords: oxygen regime, oxygen saturation, eutrophication, cold intermediate layer, Black Sea

Acknowledgements: the investigation was carried out within the framework of the state task on theme No. 0555-2021-0004 "Fundamental studies of oceanological processes which determine the state and evolution of the marine environment influenced by natural and anthropogenic factors, based on observation and modeling methods", and at the RFBR support within the framework of research project No. 19-35-90062.

For citation: Vidnichuk, A.V. and Konovalov, S.K., 2021. Changes in the Oxygen Regime in the Deep Part of the Black Sea in 1980-2019. Physical Oceanography, [e-journal] 28(2), pp. 180190. doi:10.22449/1573-160X-2021-2-180-190

DOI: 10.22449/1573-160X-2021-2-180-190

(C) A. V. Vidnichuk, S. K. Konovalov, 2021

(C) Physical Oceanography, 2021

\section{Introduction}

The Black Sea is a water body with limited water exchange with other seas. It receives $\sim 255 \mathrm{~km}^{3} /$ year of the salty Marmara Sea waters with the lower Bosphorus current [1] and a similar volume of fresh river water into the surface layer ( 338-355 km³/year) [1, 2]. The atmospheric precipitation inflow is equalized by their evaporation. This determines the presence of a permanent stable vertical stratification of waters, which results in a permanent halocline and pycnocline presence in its hydrological structure. The constant pycnocline presence limits the vertical exchange between the surface and deep-water layers, being one of the reasons for the occurrence of anaerobic conditions below the main pycnocline at depths exceeding 100-200 m. So, it is necessary to study the oxygen 
distribution dynamics in the Black Sea waters, processes of various natures that determine this dynamics on different spatio-temporal scales.

In the 1980s, the Black Sea was subjected to intense anthropogenic pressure [3-8]. The intensification of human economic activity in 1980-1990 resulted in doubling of the nutrients flux into the sea compared to previous decades. This led to the eutrophication of the Black Sea basin and more intensive oxygen consumption for the oxidation of the increased flux of organic matter. However, in the period from the mid-1990s the agricultural activity intensity was reduced, which contributed to the transition of the Black Sea ecosystem to a relatively stable state in the post-eutrophication period [8]. At the same time, it was noted that the system did not return to the state before the start of eutrophication, which leaves open the question of the mechanisms and processes determining the content, fluxes and dynamics of oxygen in the Black Sea waters.

Many works have been devoted to the study of the Black Sea eutrophication and the ongoing changes in the hydrochemical structure as a result of the increased anthropogenic impact on the sea ecosystem [3-7]; however, consideration of the post-eutrophication period ends in the mid-2000s. Some publications in recent years [9] indicated only a decrease in the oxygen content as a result of the observed warming.

The present paper is aimed to estimate the changes in the oxygen regime of the deep-water part of the Black Sea under the impact of climatic and anthropogenic factors over the past 40 years (1980-2019).

\section{Materials and Methods}

Modern data on the oxygen content and distribution in the Black Sea waters for 2015-2019 were obtained in expeditions of Marine Hydrophysical Institute (MHI) of RAS in the northwestern, northern and northeastern parts of the Black Sea (Fig. 1, b). For the earlier period of 1980-2013, the data were taken from the MHI Databank [10] (Fig. 1).

The dissolved oxygen concentration in the samples was determined by the Winkler volumetric titration method modified by Carpenter [11].

For the analysis, data were selected for the deep-water part of the Black Sea (with depths over $200 \mathrm{~m}$ ). Spatial distribution of data for 1980-2019 shown in Fig. 1, the number of dissolved oxygen measurements over the period under study is shown in Fig. 2.

Since the distribution of hydrochemical parameters in the deep-water part is isopycnic throughout the year, except for special cases of intensive winter ventilation of the pycnocline [12], it possible to average hydrochemical data over the entire sea area and time intervals using a density scale instead of a depth scale.

From the data of each expedition, deliberately false oxygen concentration values which were characterized by random outliers of values and did not correspond to similar features in the distribution of other hydrological and hydrochemical parameters were rejected. Further, the mean profiles of temperature, salinity, oxygen concentration, oxygen saturation and concentration of nitrates were calculated on a density scale. Averaging was carried out by the inverse distance method followed by additional smoothing by the low-frequency filtering method [13]. 

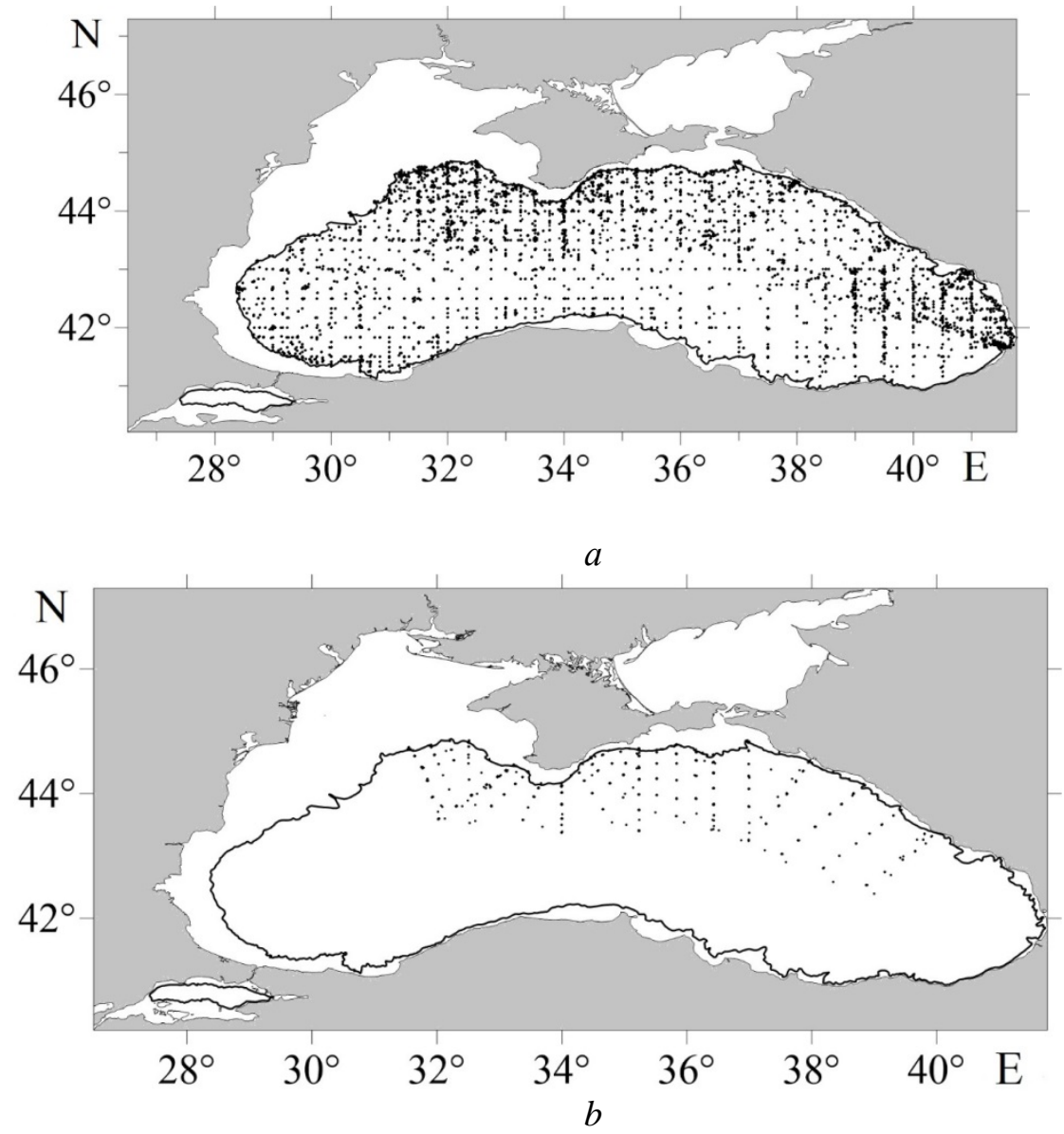

F i g. 1. Location of drift oceanographic stations for the periods 1980-2013 (a) and 2015-2019 (b). The line shows the $200 \mathrm{~m}$ isobath

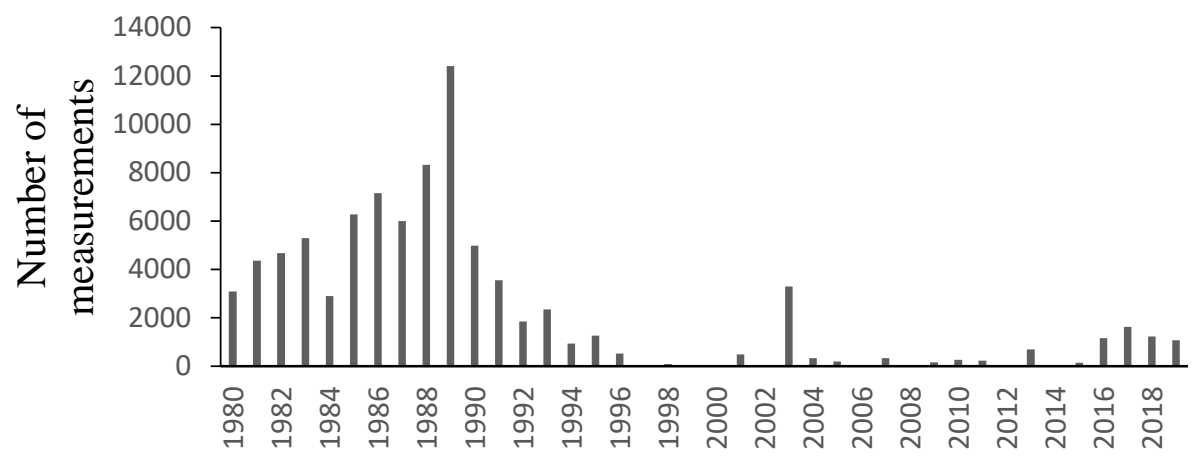

F i g. 2. Number of the dissolved oxygen measurements in the selected years within the period 1980-2019 


\section{Results and Discussion}

To exclude spatial differences in the vertical distribution of chemical characteristics associated with a change in the main pycnocline and cold intermediate layer (CIL) depth, the vertical profiles of oxygen and nitrates were analyzed in density coordinates [14-19].

In studies of long-term variations in the Black Sea eutrophication level [3-8], the following three periods of the Black Sea ecosystem state are distinguished: the first - pre-eutrophication (1960-1970s); the second - intensive eutrophication (second half of the 1980s - early 1990s) and the third - post-eutrophication (the second half of the 1990s - the first half of the 2000s). In each of these periods, the hydrochemical structure of the Black Sea passed from one stable state, characterized by reversible interannual, seasonal and shorter-period fluctuations in the system structure, to another, different only in the nature of reversible fluctuations. This phenomenon is called "regime shifts", i.e., relatively rapid changes between contrasting, stable states of the ecosystem caused by natural impact and/or anthropogenic activity [20].

In the vertical distribution of oxygen three zones can be distinguished, such as: the upper one, well ventilated and saturated with oxygen; the oxycline zone, where the oxygen concentration decreases sharply with depth; and the lower one, in which the oxygen concentration decreases from $\sim 25 \mu \mathrm{mol} / \mathrm{L}$ to its disappearance (Fig. 3, a).

The oxygen concentration in the upper layer is due to gas exchange at the boundary with the atmosphere, the intensity of photosynthesis and consumption in the processes of respiration and oxidation of organic matter and the oxygen solubility, which depends on the water temperature and salinity. Oxygen enters the oxycline layer as a result of physical transfer and is consumed mainly for the oxidation of the sinking suspended organic matter (SOM).

Fig. 3 shows the vertical distribution of oxygen and its saturation according to the data of expeditions carried out in different periods of the ecosystem state eutrophication, post-eutrophication and modern one. During the period of active eutrophication, the oxygen concentration in the oxycline layer, for example, at the depth of $\sigma_{\mathrm{t}}=14.8$, was 3 times less (Fig. 3, $a$, red line) compared to the beginning of the post-eutrophication period (Fig. 3, $a$, blue line), which reflects an oxygen consumption decrease for the SOM oxidation, the flow of which decreased during the post-eutrophication period [6, 8]. Mean profiles for 2004 and 2017 (Fig. 3, a, green and lilac lines, respectively) reflect the change in the ecosystem state. A similar trend is observed in the distribution of the oxygen saturation (Fig. 3, $b$ ), which can be caused by both climatic changes and intensification of anthropogenic activity.

In the hydrological structure of the upper sea layer, a subsurface temperature minimum layer is distinguished - a cold intermediate layer, which is formed as a result of winter convective mixing in the centers of cyclonic gyres and in the Black Sea shelf [1]. The oxygen reserve of the aerobic zone is determined by the intensity of winter convection and the rate of its consumption in redox biogeochemical and biological processes. 

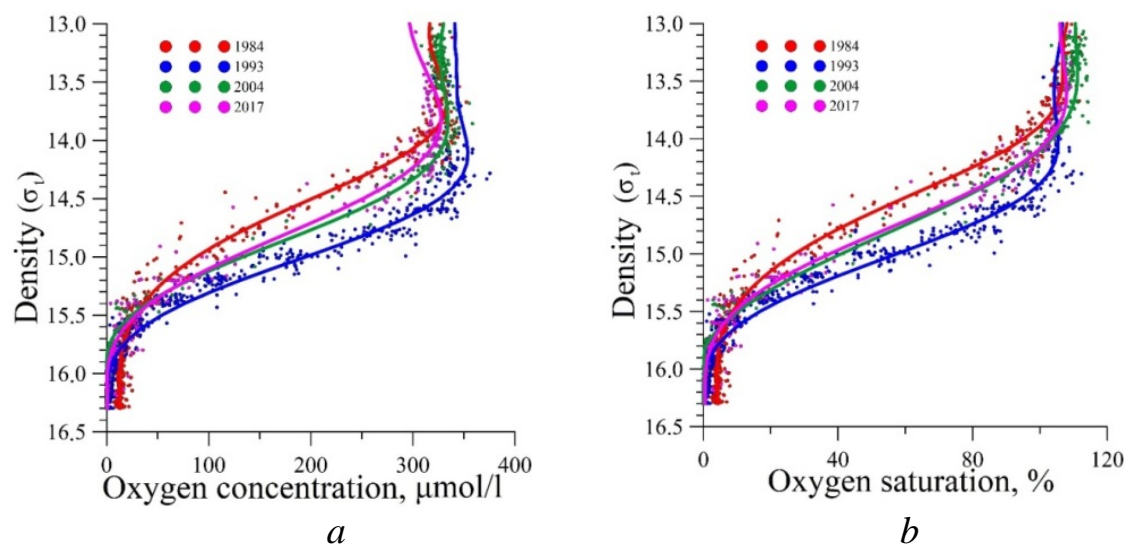

F i g. 3. Vertical distribution of the oxygen concentration $(a)$ and the oxygen saturation $(b)$ in the deep-water part of the Black Sea (the lines indicate mean profiles for each expedition)
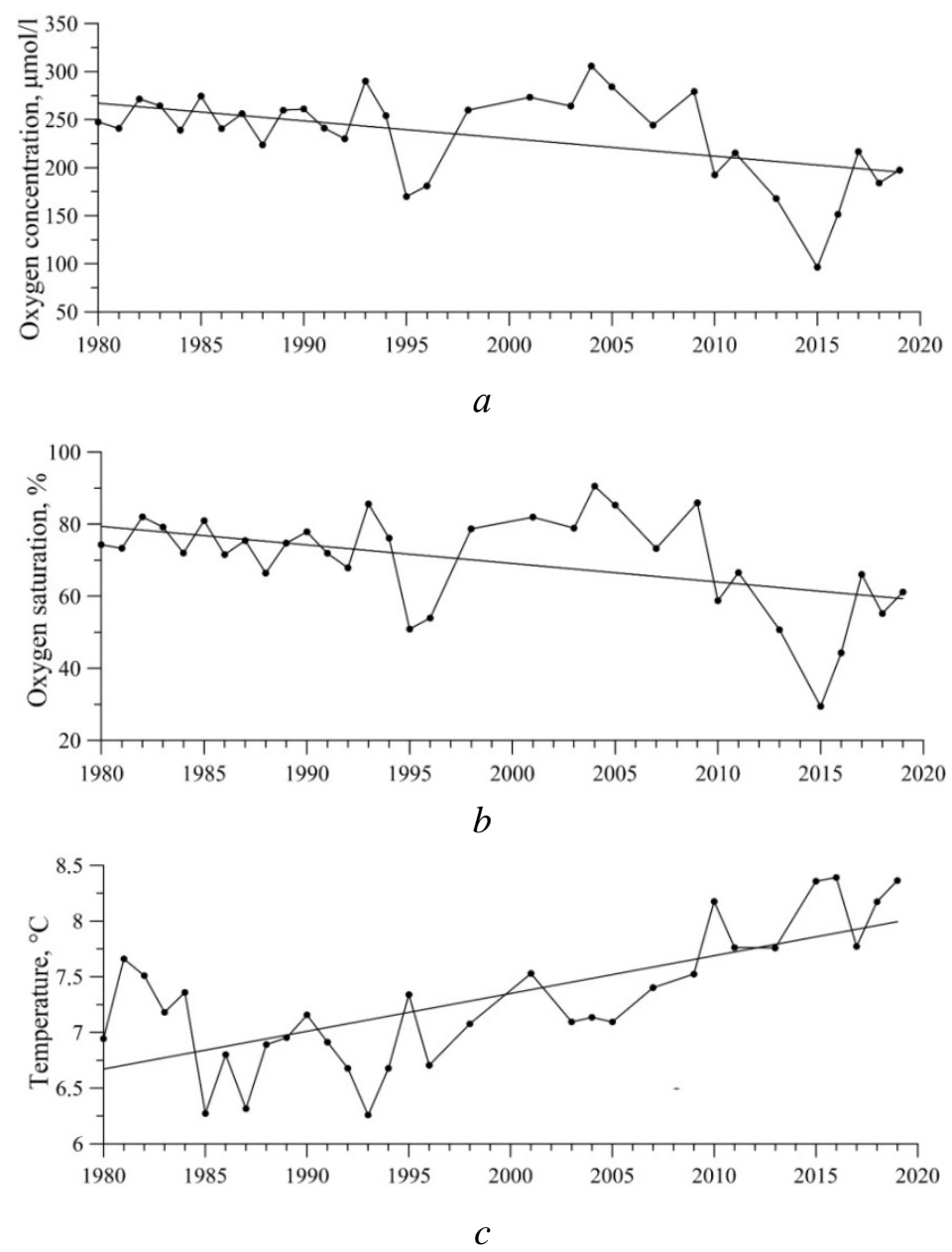

F i g. 4. Multi-year changes in the oxygen concentration $(a)$ and the oxygen saturation $(b)$ in the layer of minimum temperature, and the temperature of the cold intermediate layer core (c) 
The paper [9] analyzes the variability of the dissolved oxygen and temperature of the upper layer of the Black Sea. The principal conclusion of this work is that in the surface layer of the deep-water part of the Black Sea, there are synchronous ten-year mean variations in temperature and oxygen concentration. The authors showed that in 1970-1994 period the water temperature of the surface layer decreased by $1.5^{\circ} \mathrm{C}$, while the oxygen concentration increased by more than $25 \mu \mathrm{mol} / \mathrm{L}$. In 1995-2004 the opposite trend is observed.

The long-term variations in the concentration and oxygen saturation at the depth of the minimum temperature, i.e., in the CIL core (Fig. 4, $a, 4, b$ ) were analyzed. Correlation analysis showed a significant inverse relationship between the temperature value in the CIL core and the value of oxygen concentration in this layer; the Pearson correlation coefficient was -0.62 . It was revealed that during the period of intense eutrophication of the deep-water part of the Black Sea and in the post-eutrophication period, the oxygen concentration was relatively stable, on average, fluctuated within $250 \pm 25 \mu \mathrm{mol} / \mathrm{L}$, and the oxygen saturation was $70-80 \%$. After 2005 , there is a gradual decrease in the oxygen concentration in the CIL core, as well as in the saturation to $40-60 \%$. The decrease in the oxygen reserve in the CIL is associated not only with the transition of the hydrological structure to the warming stage, characterized by a weak intensity of water renewal in the CIL (generally below the climatic norm) and an increase in the average temperature in the core to $8^{\circ} \mathrm{C}$ (Fig. $\left.4, c\right)$ [21, 22], but also with a continuing increase in oxygen consumption.

Since the rate of CIL waters renewal at the present stage was weak*, this naturally led to an oxygen concentration decrease; a similar trend is observed in deeper layers. In the oxycline layer $\left(\sigma_{\mathrm{t}}=15.4\right)$ (Fig. $\left.5, a, 5, c\right)$ and in the region of the suboxic zone $\left(\sigma_{\mathrm{t}}=15.8\right)$ (Fig. $\left.5, b, 5, d\right)$, the oxygen concentration decrease by 2-3 times is observed in comparison with the eutrophication period of 19801990 , and a decrease in the oxygen saturation, which reflects a change in the intensity of oxygen consumption in the deep layers.

In marine ecosystems the limiting factor in the photosynthesis rate is nitrogen, which determines the level of primary and export production of phytoplankton. From 75 to $95 \%$ of SOM produced in the euphotic layer is oxidized in the Black Sea aerobic zone [8]. In the deep-water part of the sea, the regeneration of nutrients in the water column, as well as their input from deeper layers below the main pycnocline during the process of vertical water exchange, are the main input sources of mineral nitrogen compounds for the phytoplankton development [23].

Nitrates are the end product of SOM oxidation, their maximum, as a rule, is located at the depth of $\sigma_{\mathrm{t}}=15.2-15.6$.

* Belokopytov, V.N., 2017. [Climatic Changes in the Hydrological Regime of the Black Sea]: Dr. geogr. sci. diss., 377 p. 

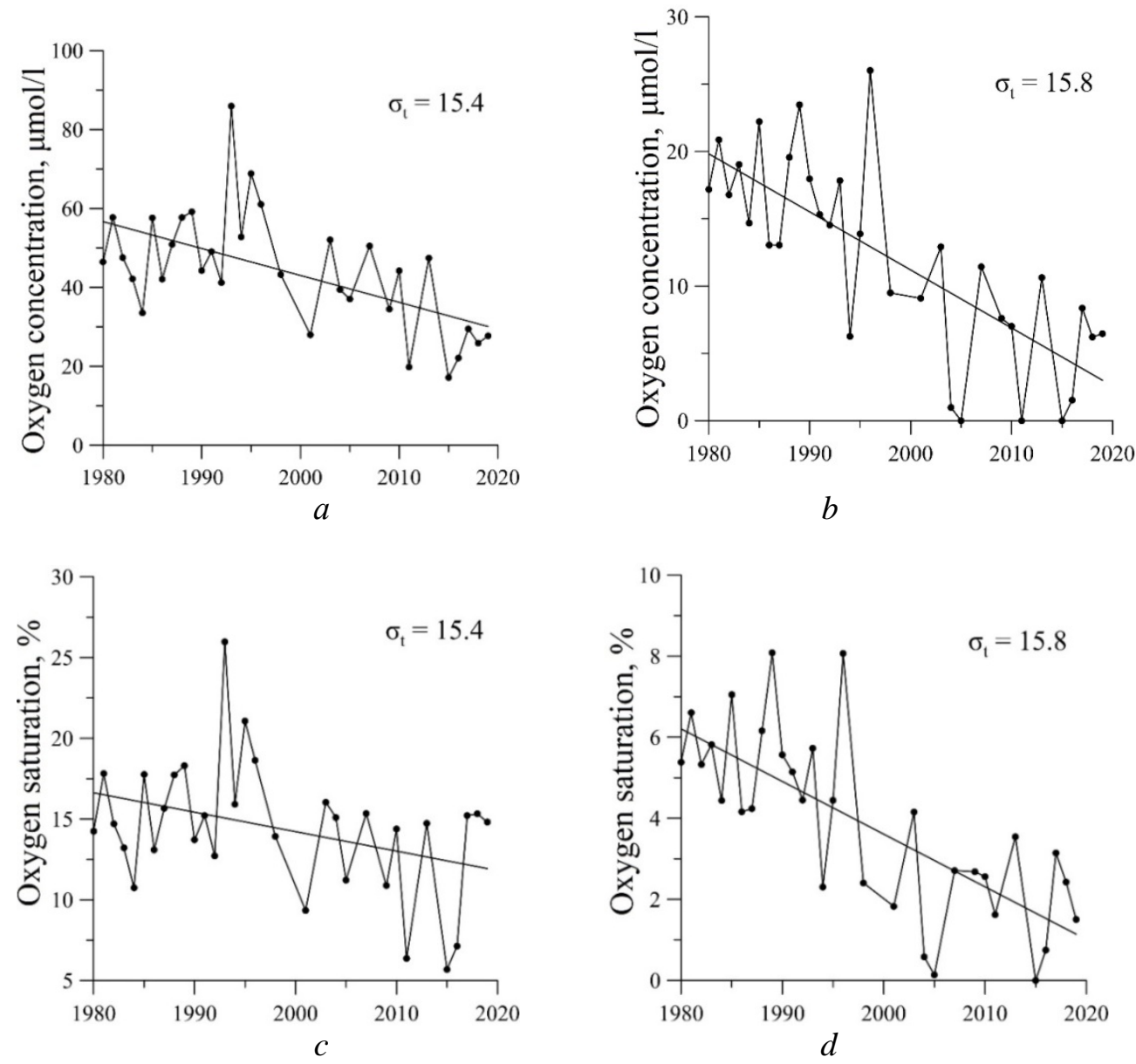

F i g. 5. Multi-year changes in the oxygen concentration $(a, b)$ and the oxygen saturation $(c, d)$ in the oxycline $(a, c)$ and in the suboxic zone $(b, d)$
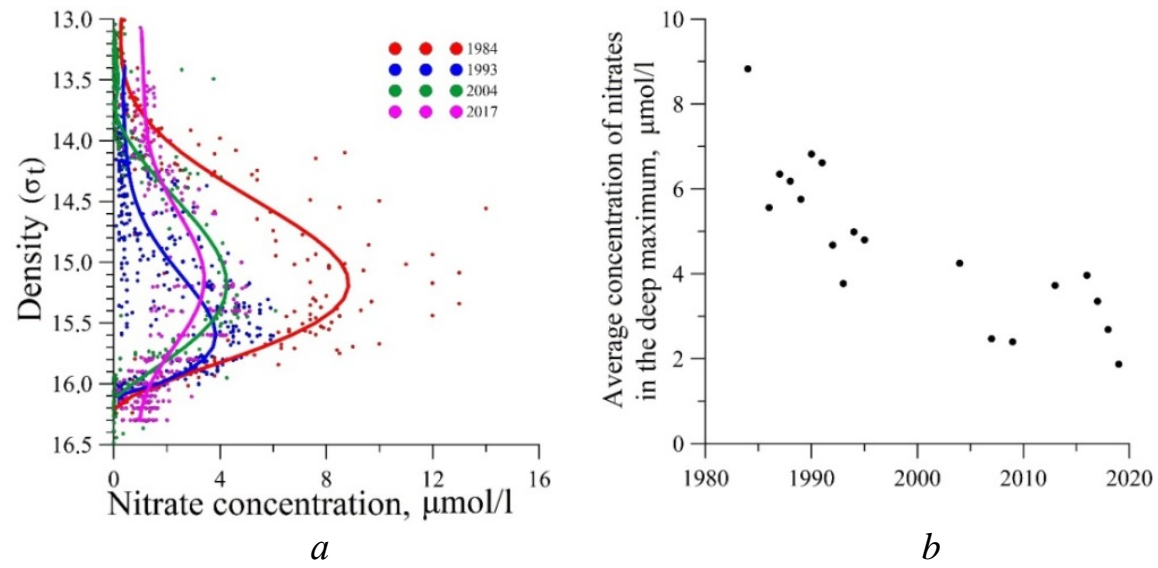

F i g. 6. Vertical distribution of the nitrate concentration $(a)$ and the nitrate average concentration in their deep maximum based on the multi-year data $(b)$ (the lines indicate average profiles for each expedition) 
As shown in [3, 4], the average nitrates concentration in the layer of their maximum increased by 2-3 times from the beginning of the 1970s to the end of the 1980s, then significantly decreased by the mid-1990s. According to the data we obtained for the modern period, the average concentration of nitrates in the layer of their maximum continues to decrease (Fig. 6). This dynamics of nitrate concentration is due to increase in the input of anthropogenic origin inorganic nitrogen from the Danube since the 1970s, which reaches a maximum in the mid1980s and then decreases by the beginning of the 2000s. [24].

In addition, since the mid-1990s the Black Sea entered a warming phase when the average winter sea surface temperature increased from $7.5^{\circ} \mathrm{C}$ in the $1990 \mathrm{~s}$ up to $9^{\circ} \mathrm{C}$ in the 2000s [22, 24]. As a result, the intensity of winter convective mixing and oxygen solubility in the seawater decreased, water masses could not penetrate to great depths, which is associated with a decrease in the oxygen inventory in the CIL (Fig. 4, $a ; 7, a$ ). The transition of nitrates from the main pycnocline layer to the upper layers also slowed down, which significantly weakened the spring phytoplankton bloom and caused a decrease in its biomass and chlorophyll $a$ concentration in the post-eutrophication period [24].

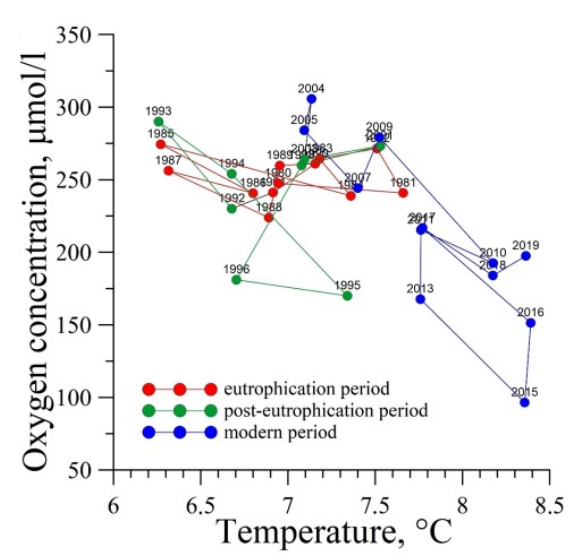

$a$

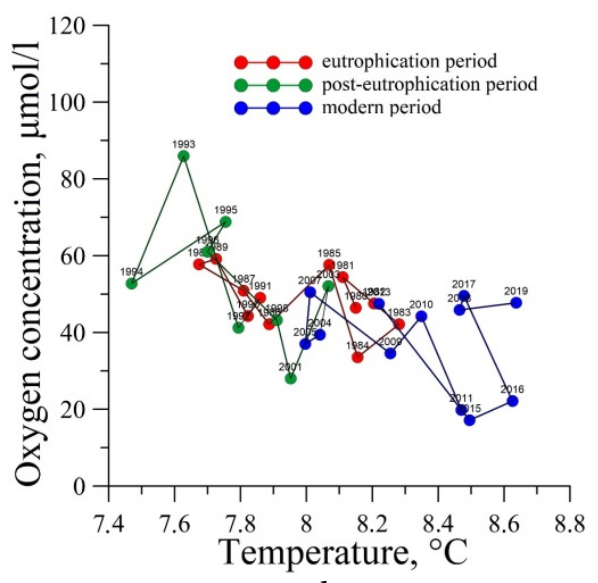

$b$

F i g. 7. T-O-diagram of the Black Sea waters at the depths of the cold intermediate layer core (a) and the middle part of the main pycnocline $\left(\sigma_{t}=15.4\right)(b)$ based on the multi-year data

The oxygen concentration in the main pycnocline layer depends on the ratio of the oxygen flux from the CIL and the oxygen consumption for the sinking organic matter oxidation. In [25], two different states of the Black Sea ecosystem were identified - the period before intense eutrophication (until the mid-1970s) and the eutrophication period (mid-1980s - early 2000s). During these two periods, the dependence of oxygen concentration on temperature is almost linear, when lower values of temperature correspond to higher values of oxygen concentration. However, at equal temperatures in the CIL and in the main pycnocline layer, the oxygen concentration during the period of intense eutrophication is much lower than before the 1970s. This may be due to an increase in the flux of sinking organic matter in the 1980s, which is confirmed by an increase in the concentration of nitrates in the layer of their maximum. 
In Fig. 7 it can be seen that in the modern period, starting from 2004, the system has passed into a qualitatively different state. The temperature both in the CIL (Fig. 4, $c ; 7, a$ ) and in the main pycnocline layer (Fig. 7, b) increased by $\sim 1^{\circ} \mathrm{C}$ in comparison with the post-eutrophication period, the oxygen concentration decreased and makes up 20-50 $\mu \mathrm{mol} / \mathrm{L}$ in the pycnocline layer, which is slightly lower than during the period of the Black Sea basin active eutrophication. At the same time, as we have demonstrated above (Fig. 6), the concentration of nitrates in the layer of their maximum continues to decrease.

\section{Conclusions}

Against the background of the trend to an increase in the temperature of the water column upper layers and a decrease in the intensity of winter convective mixing, a decrease in the oxygen inventory is observed in all layers of the aerobic zone of the Black Sea. The analysis of the data for 1980-2019 period revealed the fact that at the present stage in the ecosystem of the Black Sea basin deep-water part there has been a "regime shift" due to the combined effect of climatic changes and anthropogenic load. Climate changes lead to a decrease in the oxygen concentration in the CIL core, and hence to a lower oxygen flux into the oxycline. However, the oxygen saturation demonstrates that the eutrophication effect remains a rather important process that determines the oxygen dynamics in sea waters.

\section{REFERENCES}

1. Ivanov, V.A. and Belokopytov, V.N., 2013. Oceanography of the Black Sea. Sevastopol: MHI, 209 p.

2. Zhurbas, V.M., Zavialov, P.O., Sviridov, A.S., Lyzhkov, D.A. and Andrulionis, E.E., 2011. On the Transport of Small River Run off by an Alongshore Baroclinic Sea Current. Oceanology, 51(3), pp. 415-423. doi:10.1134/S0001437011030234

3. Konovalov, S.K., Ivanov, L.I., Murray, J.W. and Eremeeva, L.V., 1999. Eutrophication: A Plausible Cause for Changes in Hydrochemical Structure of the Black Sea Anoxic Layer. In: S. T. Beşiktepe, Ü. Ünlüata and A. S. Bologa, Eds., 1999. Environmental Degradation of the Black Sea: Challenges and Remedies. Dordrecht: Springer, pp. 61-74. https://doi.org/10.1007/978-94-011-4568-8_5

4. Konovalov, S.K. and Murray, J.W., 2001. Variations in the Chemistry of the Black Sea on a Time Scale of Decades (1960-1995). Journal of Marine Systems, 31(1-3), pp. 217-243. https://doi.org/10.1016/S0924-7963(01)00054-9

5. Yunev, O.A., Moncheva, S. and Carstensen, J., 2005. Long-term Variability of Vertical Chlorophyll a and Nitrate Profiles in the Open Black Sea: Eutrophication and Climate Change. Marine Ecology Progress Series, 294, pp. 95-107. doi:10.3354/meps294095

6. Yunev, O.A., 2011. Eutraphication and Annual Primary Production of Phytoplankton in the Deep-Water Part of the Black Sea. Oceanology, 51(4), 616. doi:10.1134/S0001437011040199

7. Mikaelyan, A.S., Zatsepin, A.G. and Chasovnikov, V.K., 2013. Long-Term Changes in Nutrient Supply of Phytoplankton Growth in the Black Sea. Journal of Marine Systems, 117118, pp. 53-64. https://doi.org/10.1016/j.jmarsys.2013.02.012

8. Yunev, O.A., Konovalov, S.K. and Velikova, V., 2019. Anthropogenic Eutrophication in the Black Sea Pelagic Zone: Long-term Trends, Mechanisms, Consequences. Moscow: GEOS, 164 p. doi:10.34756/GEOS.2019.16.37827 (in Russian).

9. Polonsky, A.B. and Kotolupova, A.A., 2019. Long-Term Variability of the Dissolved Oxygen Content and Water Temperatures in the Upper Layer of the Black Sea. Oceanology, 59(1), pp. 17-26. doi:10.1134/S000143701901017X 
10. Khaliulin, A.Kh., Godin, E.A., Ingerov, A.V., Zhuk, E.V., Galkovskaya, L.K. and Isaeva, E.A., 2016. Ocean Data Bank of the Marine Hydrophysical Institute: Information Resources to Support Research in the Black Sea Coastal Zone. Ecological Safety of Coastal and Shelf Zones of Sea, (1), pp. 90-96 (in Russian).

11. Eremeev, V.N., Konovalov, S.K. and Romanov, A.S., 1998. The Distribution of Oxygen and Hydrogen Sulfide in Black Sea Waters during Winter-Spring Period. Physical Oceanography, 9(4), pp. 259-272. https://doi.org/10.1007/BF02522712

12. Eremeev, V.N., Konovalov, S.K. and Romanov, A.S., 1997. Investigation of the Formation of Vertical Structure of Biogenic Elements Fields in the Black Sea, Using the Method of Spatial Isopycnic Analysis. Physical Oceanography, 8(6), pp. 389-402. https://doi.org/10.1007/BF02523811

13. Demyanov, V. and Savelieva, E., 2010. [Geostatistics: Theory and Practice]. Moscow: Nauka, 327 p. (in Russian).

14. Bezborodov, A.A., 1990. Relationship Between the Boundary of the Hydrogen Sulfide Zone and the Density Structure of Waters in the Black Sea. Reports of the USSR Academy of Science. Series B, (12), pp. 3-6 (in Russian).

15. Vinogradov, M.E., and Nalbandov, Y.R., 1990. Influence of Water Density Variations on the Distribution of the Physical, Chemical and Biological Characteristics of the Open Regions of the Black Sea. Oceanology, 30(5), pp. 769-777 (in Russian).

16. Codispoti, L.A., Friederich, G.E., Murray, J.W. and Sakamoto, C.M., 1991. Chemical Variability in the Black Sea: Implications of Continuous Vertical Profiles That Penetrated the Oxic/Anoxic Interface. Deep Sea Research Part A. Oceanographic Research Papers, 38(suppl. 2), pp. S691-S710. https://doi.org/10.1016/S0198-0149(10)80004-4

17. Eremeev, V.N., Konovalov, S.K. and Romanov, A.S., 1997. Investigation of the Formation of Vertical Structure of Biogenic Elements Fields in the Black Sea, Using the Method of Spatial Isopycnic Analysis. Physical Oceanography, 8(6), pp. 389-402. https://doi.org/10.1007/BF02523811

18. Yakushev, E.V., Lukashev, Yu.F., Chasovnikov, V.K. and Chzhu, V.P., 2002. Modern Notion of Redox Zone Vertical Hydrochemical Structure in the Black Sea. In: A. G. Zatsepin and M. V. Flint, Eds., 2002. Multidisciplinary Investigations of the Northeast Part of the Black Sea. Moscow: Nauka, pp. 119-133 (in Russian).

19. Sapozhnikov, V.V. and Sapozhnikov, M.V., 2002. Vertical Distribution of Principal Nutrients in the Black Sea. Oceanology, 42(6), pp. 789-794.

20. DeYoung, B., Barange, M., Beaugrand, G., Harris, R., Perry, R.I., Scheffer, M. and Werner, F., 2008. Regime Shifts in Marine Ecosystems: Detection, Prediction and Management. Trends in Ecology and Evolution, 23(7), pp. 402-409. https://doi.org/10.1016/j.tree.2008.03.008

21. Belokopytov, V.N., 2011. Interannual Variations of the Renewal of Waters of the Cold Intermediate Layer in the Black Sea for the Last Decades. Physical Oceanography, 20(5), pp. 347-355. https://doi.org/10.1007/s11110-011-9090-X

22. Konovalov, S., Belokopytov, V. and Vidnichuk, A., 2019. Oxygen Regime Shifts in the Black Sea: Climate and/or Human Effects. In: POI FEB RAS, 2019. Marine Science and Technology for Sustainable Development: Abstracts of the 26th International Conference of Pacific Congress on Marine Science and Technology (PACON-2019), July 16-19, 2019, Vladivostok, Russia. Vladivostok: POI FEB RAS, pp. 23.

23. Krivenko, O.V. and Parkhomenko, A.V., 2015. Upward and Regeneration Fluxes of Inorganic Nitrogen and Phosphorus in the Deep-Water Areas of the Black Sea. Biology Bulletin Reviews, 5(5), pp. 512-525.

24. Oguz, T. and Gilbert, D., 2007. Abrupt Transitions of the Top-Down Controlled Black Sea Pelagic Ecosystem during 1960-2000: Evidence for Regime-Shifts under Strong Fishery Exploitation and Nutrient Enrichment Modulated by Climate-Induced Variations. Deep Sea Research Part I: Oceanographic Research Papers, 54(2), pp. 220-242. https://doi.org/10.1016/j.dsr.2006.09.010 
25. Konovalov, S.K., Vidnichuk, A.V. and Orekhova, N.A., 2018. Spatio-Temporal Characteristics of the Hydrochemical Structure of Water in the Deep-sea Part of the Black Sea. In: A. P. Lisitzin, 2018. The Black Sea System. Moscow: Scientific World, pp. 106-119. doi:10.29006/978-5-91522-473-4.2018 (in Russian).

About the authors:

Anna V. Vidnichuk, Junior Research Associate, Marine Hydrophysical Institute of RAS (2 Kapitanskaya str., 299011, Sevastopol, Russian Federation), ORCID ID: 0000-0002-0889-020X, ResearcherID: AAO-2592-2020, anna_vidnichuk@mhi-ras.ru

Sergey K. Konovalov, Director, Marine Hydrophysical Institute of RAS (2 Kapitanskaya str., 299011, Sevastopol, Russian Federation), Dr. Sci. (Geogr.), corresponding member of RAS, ORCID ID: 0000-0002-5200-8448, ResearcherID: F-9047-2014, sergey_konovalov@yahoo.com

Contribution of the co-authors:

Anna V. Vidnichuk - analysis of literature data, search, processing, systematization and analysis of experimental data, analysis of results and their interpretation, preparation of the paper text

Sergey K. Konovalov - formulation of the research goals and objectives, analysis and discussion of the results, general edition of the paper

All the authors have read and approved the final manuscript.

The authors declare that they have no conflict of interest. 